\title{
Pani:Cuo Nanocomposite as Electrolyte Material for Electrochemical Supercapacitor Application
}

Ashokan S ( $\square$ ashopudur@yahoo.com )

Bannari Amman Institute of Technology, Sathyamangalam

Ponnuswamy V

Sri Ramakrishna Mission Vidyalaya College of Arts and Science

Jayamurugan $\mathbf{P}$

Adhiyamaan College of Engineering, Hosur

\section{Research Article}

Keywords: Pseudocapacitors, Voltamogramm, Electrical studies, Polyaniline

Posted Date: May 20th, 2021

DOI: https://doi.org/10.21203/rs.3.rs-528660/v1

License: (1) This work is licensed under a Creative Commons Attribution 4.0 International License.

Read Full License 


\section{Abstract}

PANI:CuO nanocomposite have been prepared by systematically adding different amounts of ammonium per sulfate as an oxidizing agent. Surface morphology shows the uniform distribution of $\mathrm{CuO}$ nanopowders in PANI matrix. TEM study gives the grain size of the as prepare PANI:CuO nanocomposite. FT-IR and UV-Vis studies confirm PANI is present and show the incorporation of $\mathrm{CuO}$ in polymer matrix. The data obtained by FT-IR measurements show the possible incorporation of $\mathrm{CuO}$ in PANI, rate of most interaction and the conductivity decrease due to the increase of APS content in the formed hybrid composites. A capacitance of polymeric materials is remarkably enhanced due to the synergistic effect between $\mathrm{CuO}$ and PANI. Moreover, the composite demonstrates good capacitive and charge/discharge properties.

\section{Introduction}

Supercapacitors are the most promising energy storage devices employed for a wide range of applications in electric vehicles and uninterruptible power supplies. They have several advantages like long life cycle, short charge-discharge time and safety [1-3]. In the recent years, supercapacitors have drawn more and more attention as they have the advantage of both rechargeable batteries and dielectric capacitors. Presently, many laboratories are actively engaged in preparing flexible, lightweight and environmentally friendly materials for development of supercapacitors.

Supercapacitors can develop either with carbon based materials or pseudocapacitive materials. Conducting polymers and carbon based conducting polymer nanocomposites are well known pseudocapacitive materials. Pseudocapacitance is responsible for faradic reactions that take place at the interface $[4,5]$. The performance supercapacitor can characterize by many factors, such as large magnitude of current, a rectangular type of voltammo gram and symmetry of anodic and cathodic directions.

In recent years, the development inorganic/polymer hybrid materials on nanometer scale have received significant attention due to a wide range of potential applications in optoelectronic devices [6-8] and in field effect transistors [9].

Moreover, the synthesis of PANI-metal oxide composites nanofibers, where the size, morphology and conducting properties of the PANI were greatly influenced by the addition metal oxides such as $\mathrm{Fe}_{2} \mathrm{O}_{3}$, $\mathrm{TiO}_{2}, \mathrm{~V}_{2} \mathrm{O}_{5}, \mathrm{SnO}_{2}$ and $\mathrm{ZnO}$ have incorporated into PANI [10-15].

In our earlier work, we have reported a comparative study of pure polyaniline with various oxidants using (APS, $\mathrm{K}_{2} \mathrm{Cr}_{2} \mathrm{O}_{7}$ and $\mathrm{FeCl}_{3}$ ) by a template free method. The main advantages of various oxidants are soluble in most of the organic solvent; the organic peroxide reduces the possibility of over oxidation of PANI during exothermic reaction. The synthesis of conductive polymers such as polyaniline and polypyrrole relies on strong oxidizing agents as initiators. The most electrical conductivity was APS doped PANI's are due to the formation of better charge transport network [16]. 
To the best of our knowledge, this is the first ever attempt made to study these composites are various oxidant ratios and focused on the effect of the oxidizer on the electrochemical performance of the composites.

\section{Experimental}

The aqueous solution of $\mathrm{CuCl}_{2} \cdot 6 \mathrm{H}_{2} \mathrm{O}(0.4 \mathrm{M})$ is prepared in a round-bottomed flask. Then $2 \mathrm{ml}$ of acetic acid $\left(\mathrm{CH}_{3} \mathrm{COOH}\right)$ is added and heated at $100^{\circ} \mathrm{C}$ with constant stirring. Finally, $8 \mathrm{M}$ of $\mathrm{NaOH}$ is added to above heated solution till the $\mathrm{pH}$ reaches 7 . The large quantity of black precipitate is obtained from the solution. The precipitate is centrifuged and washed 3-4 times with de-ionized water and dried in air for 24 hours. The prepared samples are characterized to confirm the presence of CuO nanopowder.

In a typical synthesis, $0.1 \mathrm{M}$ aniline monomer and hydrochloric acid $(\mathrm{HCl}) 0.1 \mathrm{M}$ are dissolved in $100 \mathrm{ml}$ of de-ionized water and then $0.1 \mathrm{M}$ of ammonium per sulfate (APS) was added to the mixture with constant stirring. The polymerization reaction is carried out under static conditions at room temperature for 24 hours. The synthesized polymer product was filtered, dried and collected for studies.

Aniline monomer of $0.1 \mathrm{M}, 1 \mathrm{M}$ of $\mathrm{HCl}$ and required quantity $(200 \mathrm{mg})$ of $\mathrm{CuO}$ powder are mixture and stirred for 10 minutes with double distilled water. APS $0.1 \mathrm{M}$ is added drop-wise to the above solution with constant stirring. The dark green PANI:CuO:APS ${ }_{x}$ hybrid nanocomposite attained dark blue color with continued stirring for 24 hours. Finally, the resultant composite is washed with de-ionized water, methanol and acetone to remove excess acid and dried at $60^{\circ} \mathrm{C}$ for 24 hours in a vacuum oven. Through the same process PANI:CuO:APS $(x=0.15 \mathrm{M}, 0.3 \mathrm{M}$ and $0.5 \mathrm{M})$ of APS are synthesized. The synthesized samples are finally grained and the products of inorganic hybrid composites are obtained.

\section{Results And Discussion}

The prepared samples are characterized to elucidate the morphological, structural, optical and electrical properties with various characterization techniques.

The effect of the metal oxide, doping acid and oxidant on the morphology of CuO, PANI:CuO:APS hybrid is brought out through the SEM images and shown in Fig. 1(a-e). Fig. 1a shows the surface morphology of the $\mathrm{CuO}$ nanopowders which are aggregate easily in aqueous solution due to their high surface energy and irregular shape. A few nanofibres (104 nm) and some clusters (Fig. 1d) are observed in PANI:CuO:APS ${ }_{0.3 \mathrm{M}}$ hybrid nanocomposite [17-19].

The PANI:CuO:APS ${ }_{0.3 \mathrm{M}}$ surface with fussy interconnected nanofibers is clearly seen from SEM image of hybrid nanocomposite in Fig. 1(d\&e). These SEM images show that the loading of APS oxidant agents has a strong effect on the PANi morphology. The type and concentration of oxidant agents play a major role in determining the surface morphology, which in turn changes with wt. ratio of oxidant. 
Fig. 2a shows the TEM micrograph of PANI:CuO hybrid nanocomposite synthesized with $0.3 \mathrm{M}$ of APS oxidant. The presence of $\mathrm{CuO}$ phase with varied size in the polymer has also been confirmed. The size of the particle observed in TEM image is in the range $32 \mathrm{~nm}$ which agrees the calculated value using Scherrer formula.

Fig. $2 \mathrm{~b}$ shows the selected area diffraction pattern (SAED) of the as prepare PANI:CuO hybrid nanocomposite. It shows that all the particles are well crystallized. The diffraction rings on SAED image match with the peaks in the XRD pattern which also proves the monoclinic structure of as prepare CuO nanopowders [20].

Fig. 3a shows the presence on early stoichiometric CuO nanopowders. The calculated weight \% of copper and oxide from EDAX is 64.56 wt. \% and 35.44 wt. \%, which confirms the pure CuO nanopowders are formed. It has no traces of other impurities. Fig. $3 \mathrm{~b}$ shows the EDAX performed to determine the atomic percentage of PANI:CuO hybrids. The quantitative analysis result indicates the presence of carbon, sulphur, copper and oxide in the formed hybrids.

Fig. 4 shows the FT-IR spectra of PANI, CuO and PANI:CuO composite samples obtained from different synthesis. Their vibrational assignments are presented in Table 1 and Table 2. The formation of polyaniline through chemical synthesis, its $\mathrm{HCl}$ doped state and the presence of vibration bands at 3425 , 2924, 2330, 1556, 1452, 1296, 1110, 810 and $617 \mathrm{~cm}^{-1}$ are shown in Fig. 4a. The $3425 \mathrm{~cm}^{-1}$ vibration band is attributed to the stretching vibration of secondary amines. The vibration band seen around 2924 $\mathrm{cm}^{-1}$ is ascribed to the aromatic $\mathrm{C}-\mathrm{H}$ vibration. The $1556 \mathrm{~cm}^{-1}$ vibration band is due to the $\mathrm{C}=\mathrm{C}$ double bond of quinoid rings, whereas $1452.32 \mathrm{~cm}^{-1}$ vibration band arises due to the vibration of $\mathrm{C}=\mathrm{C}$ double bond associated with the benzenoid ring. The peak at $1500 \mathrm{~cm}^{-1}$ may be due to strong symmetrical bending band, and it may occur due to secondary aromatic amines. The vibration band at $1110 \mathrm{~cm}^{-1}$ is due to the presence of the $\mathrm{C}-\mathrm{N}$ double bond and indicative of protonation. The vibration band at $810 \mathrm{~cm}^{-1}$ is attributed to a $\mathrm{C}-\mathrm{H}$ vibration band of para-linked phenyl ring which confirms the predominance of paracoupling in polymerization of aniline.

Fig. $4 \mathrm{~b}$ shows the presence of peaks at 453,494 and $609,919,1498,2353$ and $3466 \mathrm{~cm}^{-1}$ correspond to characteristic stretching vibrations of $\mathrm{Cu}-\mathrm{O}$ bond in the $\mathrm{CuO}$ nanopowder $[21,22]$. The broad absorption peak at $3466 \mathrm{~cm}^{-1}$ is caused by the adsorbed water molecules since the nanocrystalline materials exhibit high surface to volume ratio and absorb moisture. The peaks observed confirm the formation of CuO nanopowders [23]. The FT-IR spectra for PANI: CuO: APS ${ }_{x}(x=0.1$ to $0.5 \mathrm{M}$ of APS) hybrid nanocomposite is shown in Fig. 4(c-f). It shows some shift in the wave number and change in the peak intensity on comparing PANI with CuO.

The most prominent changes are: (i) shift of $=\mathrm{C}-\mathrm{H}$ in plane vibration peak to high wave number, i.e., from $1110 \mathrm{~cm}^{-1}$ in PANI to $1142 \mathrm{~cm}^{-1}$ in composite with increased intensity, (ii) shift of $\mathrm{C}-\mathrm{N}$ structure, bending 
to higher values i.e., from 1296 to $1305 \mathrm{~cm}^{-1}$ and iii) the presence of 1450 and $1494 \mathrm{~cm}^{-1}$ peaks correspond to benzenoid ring vibration and $\mathrm{C}=\mathrm{C}$ bond in composite.

This change is due to the conjugation loss and molecular order in the synthesized PANI with CuO. Since the frequency of vibration is directly proportional to force constant of bonds, a shift in $=\mathrm{C}-\mathrm{H}$ in plane vibration to lower side indicates the localization of electrons in the benzenoid ring. This also indicates the shortening of $\mathrm{N}-\mathrm{C}$ bonds and suggests the localization of p-orbital electrons on the $\mathrm{N}$. In addition, the enhancement of the peak intensity $(\mathrm{C}-\mathrm{H}$ in plane vibration) indicates the dipole moment increase.

With an equal mole ratio of PANI and $\mathrm{CuO}$ nanopowders and the addition of APS lead the localization of electrons in the formed PANI composites. Moreover, the growth ratio of the PANI backbone could be influencing the presence of the $\mathrm{CuO}$ and APS, which has the ability to influence the dopant anions.

X-ray diffraction patterns of $\mathrm{CuO}$ nanopowders, PANI, PANI:CuO:APS , hybrid nanocomposite are shown in Fig. 5 (inset the Fig.). All the peaks in diffraction pattern show the monoclinic structure of $\mathrm{CuO}$ and follow the JCPDS No. (89-5895, 048-1548 and 80-1917). The Miller indices are identified and structural parameter values are listed in Table 3. The lattice parameters are calculated from XRD data. The crystallite size of the CuO nanopowders is calculated using Debye-Scherer formula given in eqn. 1 [24].

$$
D=\frac{0.9 \lambda}{\beta \operatorname{Cos} \theta}
$$

where, $D$ is the crystalline size, $\lambda$ is the wavelength $(=0.1540 \mathrm{~nm}), \beta$ is the full width at half maximum of the peak in radian, $\theta$ is the Bragg diffraction angle at peak position in degrees. The maximum and minimum crystallite sizes are found to be $46.36 \mathrm{~nm}$ and $15.8 \mathrm{~nm}$.

Fig. 5a shows the amorphous nature of PANI. The peak at $25.33^{\circ}$ is ascribed to the periodicity perpendicular to the polymer chain, while those other peaks are likely due to the branches of $\mathrm{HCl}$ doped PANI [25,26].

The characteristic peaks ascertained from the XRD of PANI:CUO:APS ${ }_{x}$ hybrid nanocomposites formed at different mole ratios $(x=0.1,0.15,0.3$ and $0.5 \mathrm{M})$ are shown in Fig. $5(b-f)$. The presence of sharp and distinct peaks indicates the nanocrystalline nature of $\mathrm{CuO}$. The $2 \theta$ values $25.2^{\circ}, 35.43^{\circ}, 38.6^{\circ}, 48.66^{\circ}$, $58.6^{\circ}, 61.48^{\circ}$ and $68.8^{\circ}$ are consistent with the JCPDS No. (89-5895, 048-1548, 80-1917), which demonstrates the monoclinic structure of $\mathrm{CuO}$. PANl:CuO hybrid nanocomposites structural parameter values are listed in Table 4.

Fig. 5 shows a small peak around $25^{\circ}$ indicates the crystallinity of PANI. As the APS content is increased, the amorphous nature of PANI slightly changes and the composite powder becomes strongly oriented along $35^{\circ}$. The strong peaks in the XRD pattern of nanocomposites verify the presence of copper nanopowders in the polyaniline matrix. Obviously, these differences should have some influence on the 
crystallinity of the prepared hybrid composite. Moreover, it is concluded that the degree of crystallinity is associated with the supermolecular organization of PANI chains. The fraction of crystalline phase increases with molecular weight of the grown PANI.

Fig. 6 shows the optical absorbance with respect to wavelength for PANI, CuO and PANI:CuO:APS hybrid nanocomposites. Two absorption bands at $355 \mathrm{~nm}$ and $602 \mathrm{~nm}$ are observed for PANI. The first absorption band is usually attributed to the $\Pi-\Pi^{*}$ electronic transition of the benzene rings and the second absorption band is assigned to the benzenoid to quinoid excitonic transition. The position of the peak is related to the degree of conjugation between adjacent phenylene rings in the polymer chain [27, 28]. The forced planarization of $\Pi$-system induced by aggregation leads to the increased conjugation with decreased band gap.

The absorption bands of PANI appear in the range $~ 320-370 \mathrm{~nm}$ and $542-642 \mathrm{~nm}$ for $\mathrm{CuO}$ and APS loadings indicate the shifting of absorption bands and the presence of strong interaction between PANI and CuO. However, the band at $\sim 602 \mathrm{~nm}$ almost disappears in the composite formed with $\mathrm{CuO}$ and increased content of APS. It is interesting to note that the absorption at $\sim 602 \mathrm{~nm}$ is due to the benzenoid to quinoid excitonic transition and is shifted to $642 \mathrm{~nm}$ (Fig. 6e) for $0.5 \mathrm{M}$ of PANl:CuO hybrid nanocomposite. The optical band gap of all samples is estimated according to the

relation [29]:

$a h \gamma=B\left(h v-E_{g}\right)^{2}(2)$

where, $h v$ is the incident photon energy, $\mathrm{a}$ is the absorption coefficient, $B$ is a materials dependent constant and $E_{g}$ is the optical band gap.

The optical band gaps $2.64 \mathrm{eV}$ and $2.17 \mathrm{eV}$ to $2.7 \mathrm{eV}$ are obtained for $\mathrm{CuO}$ and PANI:CuO nanocomposite from the Fig. 7 (inset Fig.). The increase of $\mathrm{CuO}$ band gap is due to the addition of APS and the formation of polaron in the nanocomposite.

The PL emission peaks of PANI and PANI:CuO:APS ${ }_{x}$ hybrids are shown in Fig. 8 (a-e). The presence of an excitation band at $342 \mathrm{~nm}$ and emission peak at $410 \mathrm{~nm}$ (blue) for PANl as shown as in Fig. 8a. The hybrid PANI:CuO:APS ${ }_{\mathrm{x}}$ hybrid nanocomposites are perceived at different excitation wavelengths $~ 330$ $335 \mathrm{~nm}$ along with an emission peak at $520 \mathrm{~nm}$ as shown in Fig. 8 (b). Addition of small quantity of CuO nanopowders leads to the intensity increase at blue and green regions of visible spectrum due to the development of more density of states in the energy band.

The increase of APS from $0.1 \mathrm{M}$ to $0.5 \mathrm{M}$ develops peaks at two wave lengths as shown in Fig. 8. The electrons donated by PANI can move easily through the $\mathrm{CuO}$ nanopowders and this combination enhances the electron mobility in the nanocomposites [30]. 
The I-V characteristics (Fig. 9(a-e)) of PANI:CuO:APS ${ }_{x}$ hybrid nanocomposite $(x=0.1,0.15,0.3 \& 0.5 \mathrm{M})$ show a linear increase in current with applied voltage and temperature $\left(40\right.$ to $\left.150{ }^{\circ} \mathrm{C}\right)$ and confirm the ohmic behavior. It is observed from the Fig. 10 that the electrical conductivity of PANI:CuO:APS $0.1 \mathrm{M}$ hybrid increases with APS content and attains its maximum for PANI:CuO:APS ${ }_{0.3 \mathrm{M}}$ hybrid nanocomposites.

Further increase of APS (0.5 M) content leads the conductivity decrease as shown in the Fig.10. However, the polaron bands of these polymers remain unchanged even with the increase of oxidant concentration which also decreases the conductivity to a large extent.

Fig. 11 (a \& e) show the photoconductivity change of PANI and PANI:CuO:APS ${ }_{0.5 \mathrm{M}}$ hybrid nanocomposites. The photo conducting is due to the reduction of charge carriers in the presence of radiation. When the sample is exposed to light irradiation, recombination of electrons and holes takes place which reduces the charge carrier concentration with increased positive photoconductivity as shown in Fig. 11. The above study concludes the better response of PANI:CuO nanocomposites compared with $\mathrm{HCl}$ doped PANI.

The C-V curves of PANI, CuO and PANI:CuO hybrid composites are recorded at a scan rate $10 \mathrm{mVs}^{-1}$ in room temperature and are shown in Fig. 12(a-c). The above

An optimized conditions different weight percentage of oxidant $(x=0.1,0.15,0.3 \& 0.5 \mathrm{M})$ PANl:CuO hybrid composites samples. Electrical studies reveal the electrical conductivity of PANI:CuO:APS $0_{0.1 \mathrm{M}}$ hybrid increases with APS content and attains its maximum for PANI:CuO:APS ${ }_{0.3 \mathrm{M}}$ hybrid nanocomposites.

Fig. 12a shows the broad redox couple of PANI observed at positive and negative potentials at $0.90 \mathrm{~V}$ and $-0.27 \mathrm{~V}$, respectively. Fig. $12 \mathrm{~b} \& \mathrm{c}$ show the absence of peaks for $\mathrm{CuO}$ and the occurrence of redox couples for $\mathrm{CuO}$ incorporated PANI composites. Among these redox peaks, an individual sharp oxidative and a broad reductive peak are recorded at $1.25 \mathrm{~V}$ and $-0.57 \mathrm{~V}$, respectively. The redox couple of $\mathrm{CuO}$ is found to be shifted from 0.90 to $1.25 \mathrm{~V}$ (oxidative peak) and -0.27 to $-0.57 \mathrm{~V}$ (reductive peak) due to electrostatic and hydrogen bonding interactions, when PANI:CuO composite is formed.

The mobility of the counter ions through the charge transport supporting electrolyte and the presence of redox process are established. The calculated specific capacitance (C) values are listed in Table. 5

The specific capacitance value of the supercapacitor with PANI:CuO composite electrolytes is maximum compared with acid doped PANI and pure $\mathrm{CuO}$ nanopowder due to the high cycling reversibility. The capacitance of the polymeric materials is remarkably enhanced due to the synergistic effect between $\mathrm{CuO}$ and PANI. Moreover, the composite demonstrates good capacitive and charge/discharge properties [31].

\section{Conclusion}

PANI, PANI:CuO:APS ${ }_{x}$ hybrid nanocomposites are synthesized and investigated by FT-IR, UV-Vis, SEM with EDAX, TEM, PL and electrical conductivity studies. SEM morphology shows the uniform distribution of 
$\mathrm{CuO}$ nanopowders in the PANI matrix. The strong effect due to the incorporation of $\mathrm{CuO}$ and the increase of APS content develops different morphologies for PANI:CuO:APS ${ }_{x}$ hybrid nanocomposites. TEM study reveals the presence of $30 \mathrm{~nm}$ sized particles in the PANI:CuO:APS ${ }_{0.3 \mathrm{M}}$ hybrid nanocomposite. FT-IR spectra confirm the incorporation of $\mathrm{CuO}$ in PANI and the increased interaction due to the addition of APS. The addition of APS introduces a structural change in the samples synthesized (amorphous to crystalline) and develops an orientation in the crystalline sample along $35^{\circ}$ as observed from the XRD studies. PL studies show the emission peaks of PANI and the PANI:CuO hybrid peak bordering with reduced intensities. The loss of conductivity in the PANI:CuO:APS ${ }_{x}$ hybrid nanocomposites with the increase of APS ( 0.15 to $0.5 \mathrm{M})$ content has been confirmed from the DC conductivity studies. The electrolytes prepared with PANI:CuO composites have maximum specific capacitance value compared with acid doped PANI and pure CuO nanopowder.

\section{Declarations}

\section{Acknowledgement}

The authors are thankful to Sophisticated Test and Instrumentation Center, Cochin, Kerala, for providing instrumental facilities (SEM). Also, would like to thank Birla Institute of Technology \& Science, Hyderabad, Andhra Pradesh. I especially like to thank Barathidasan University, Thirchy for providing Electrical C-V instrumental facilities.

\section{References}

1. Gangopadhyay and A. De, Chem. Mater. 12 (2000) 608.

2. Karthikeyan, D. Kalpana, N.G. Renganathan, Ionics. 15 (2009) 107.

3. Hakamada, A. Moriguchi, M. Mabuchi, J. of Pow. Sour. 245 (2014) 324.

4. Peng, S. Zhang, D. Jewell, G.Z. Chen. J. of Electroana. Chem. (2008) 1.

5. A. Snook, P. Kao, A.S. Best, J. of Pow. Sour. (2011) 196.

6. Kim, K. Lee, P. Huh, D. Lee, N. Ju Jo, J. Oo Lee, Synth. Met. 159 (2009) 1369.

7. Su, T. Wang, S. Zhang, J. Song, C. Mao, H. Niu, B. Jin, J. Wu, Y. Tian, Sol. Stat. Sci. 14 (2012) 677.

8. D. Munteanu, Y. Okamoto. L. Gorton,Anal. Chim. Acta. 476 (2003) 43.

9. Calvo-Marzal, C. Torres, K.Y. Hoehr, N.F. Kubota, Sens. Actuat. B 100 (2004)333.

10. Zhai, Y. Dou, D. Zhao, P.F. Fulvio, R.T. Mayes, S. Dai. Adv. Mat. 23 (2011) 4828.

11. Xi, D. Ren, J. Luo, Y. Zhu, J. of Electroana. Chem. 650 (2010) 127.

12. Jampani, A. Manivannan, P.N. Kumta, Electrochem. Soci. Inter. (2010) 57.

13. Peng, S. Zhang, D. Jewell, G.Z. Chen. J. of Electroana. Chem. (2008) 1.

14. A. Snook, P. Kao, A.S. Best, J. of Pow. Sour. (2011) 196.

15. Kim, K. Lee, P. Huh, D. Lee, N. Ju Jo, J. Oo Lee, Synth. Met. 159 (2009) 1369. 
16. Ashokan, V. Ponnuswamy, P. Jayamurugan., Mat. Sci. in Semicond Pro. 30 (2015) 494-501.

17. M. Jundale, S. T. Navale, G. D. Khuspe, D. S. Dalavi, P. S. Patil, V. B. Patil., J. Mater Sci:Mater Elect. (2013).

18. Jundale, S. Pawar, M. Chougule, P. Godse, S. Patil, B. Raut, S.J. Sens. Tech. (2011) 36.

19. M. Jundale, P.B. Joshi, S. Sen, V.B. Patil, J. Mat.Sci. Mater. Electron 23 (2012) 1492.

20. Wang, J. Zhang, J. J. Zhu, H. Y. Chen, J. Cryst. Growth. 88 (2002) 244.

21. A. Dar, Y.S. Kim, W.B. Kim, J.M. Sohn, H.S. Shin, Appl. Surf. Sci. 254 (2008) 7477.

22. Balamurugan, B.R. Mehta, Thin Solid Films. 396 (2001) 90.

23. Ibrahim Y. Erdogan, O.Gullu, of Alloy. Comp. 492 (2010) 378.

24. A. Dar, Y.S. Kim, W.B. Kim, J.M. Sohn, H.S. Shin, Appl. Surf. Sci. 254 (2008) 7477.

25. Xia, Q. Wang, Chem. Mater. 14 (2002) 2158.

26. Radoic, Z. S.aponjic, J. Nedeljkovic, G.C. Marjanovi, Synth. Met. 160 (2010) 1325.

27. K. Ram, O. Yavuz, V. Lahsangah, and M. Aldissi, Sens. and Actuat. B. 106 (2005) 750.

28. Pron, P. Rannou, Prog. Polym. Sci. 27 (2002) 135.

29. F. Mott, E.A. Davies, Elect. Proc. in Non-Cry. Mat. (2012).

30. L. Wise, G. E. Wnek, D. Trantlolo, T. M. Cooper, and J. D. Gresser, Marcel Dekker (1998).

31. Calvo-Marzal, C. Torres, K.Y. Hoehr, N.F. Kubota, Sens. Actuat. B 100 (2004)333.

\section{Tables}

Table 1 FT-IR spectra adscription of CUO, PANI and PANI:CuO 


\begin{tabular}{|llll|}
\hline CuO & HCl-PANI & HCl-PANI:CuO:APS & \\
\hline 453 & - & 450 & \multicolumn{1}{c|}{ Adscription } \\
\hline 494 & 509 & 512 & Cu-O bond \\
\hline 609 & 617 & 615 & Cu-O bond \\
\hline- & 810 & 826 & Cu-O bond \\
\hline- & 879 & 865 & C-H in plane bending vibration \\
\hline- & 1110 & 1042 & C-H out plane bending vibration \\
\hline- & 1296 & 1301 & C-H in plane bending vibration \\
\hline 1498 & 1450 & 1494 & Aromatic C-N stretching, amine group \\
\hline- & 1556 & 1557 & C-N strecthing of benenoid rings \\
\hline- & 2924 & 2926 & C-N stretching of quinoid rings \\
\hline 3466 & 3425 & 3567 & The aromatic C-H stretching \\
\hline
\end{tabular}

Table: 2 Characteristics absorption bands of PANI:CUO:APS hybrid nanocomposite

\begin{tabular}{|lllll|}
\hline Composite A & Composite B & Composite C & Composite D & Adscription \\
$\mathbf{0 . 1 M}$ of APS & $\mathbf{0 . 1 5 M}$ of APS & $\mathbf{0 . 3}$ of APS & $\mathbf{0 . 5}$ of APS & \\
\hline 450 & 486 & 490 & 442 & Cu-O bond \\
\hline 512 & 527 & 577 & 505 & Cu-O bond \\
\hline 615 & 624 & 647 & 657 & Cu-O bond \\
\hline 826 & 826 & 826 & 826 & C-H out plane bending vibration \\
\hline 1142 & 1173 & 1175 & 1158 & C-H in plane bending vibration \\
\hline 1301 & 1297 & 1300 & 1303 & C-N stretching, amine group \\
\hline 1494 & 1491 & 1495 & 1502 & C-N stretching of benenoid rings \\
\hline 1557 & 1579 & 1579 & 1579 & C-N stretching of quinoid rings \\
\hline 3048 & 2976 & - & 3070 & The aromatic C-H stretching \\
\hline 3567 & 3708 & 3758 & - & H-OH \\
\hline
\end{tabular}

Table 3 Structural parameters of pure CuO nanopowder 


\begin{tabular}{|lllll|}
\hline Pos. [ ${ }^{\circ}$ 2Th.] & Height [cts] & FWHM & hkl & Crystalline Size \\
\hline 35.49 & 332 & 0.18 & 020 & 46.33 \\
\hline 38.73 & 186 & 0.28 & 020 & 30.07 \\
\hline 48.74 & 58 & 0.21 & 202 & 41.52 \\
\hline 53.48 & 16 & 0.40 & 014 & 22.23 \\
\hline 58.33 & 51 & 0.21 & 123 & 43.31 \\
\hline 61.52 & 54 & 0.27 & 222 & 34.23 \\
\hline 66.13 & 37 & 0.60 & 204 & 15.79 \\
\hline 68.01 & 47 & 0.31 & 311 & 30.92 \\
\hline 75.08 & 25 & 0.40 & 303 & 25.04 \\
\hline
\end{tabular}

Table 4 The structural parameters of PANI:CuO hybrid nanocomposite

\begin{tabular}{|lllll|}
\hline Pos. ${ }^{\circ}{ }^{\circ}$ Th.] & Height [cts] & FWHM Left [ ${ }^{\circ}$ 2Th.] & hkl & Crystalline Size \\
\hline $19.5(3)$ & $15(5)$ & $2.6(4)$ & 010 & 31.00 \\
\hline $25.4(2)$ & $31(3)$ & $7(1)$ & 002 & 11.64 \\
\hline $35.433(4)$ & $247(11)$ & $0.228(9)$ & 020 & 36.50 \\
\hline $38.677(5)$ & $236(11)$ & $0.27(2)$ & 020 & 31.17 \\
\hline $48.66(1)$ & $65(11)$ & $0.19(6)$ & 202 & 45.88 \\
\hline $58.25(3)$ & $31(10)$ & $0.2(1)$ & 123 & 45.46 \\
\hline $61.48(1)$ & $67(6)$ & $0.13(3)$ & 222 & 71.09 \\
\hline $65.92(5)$ & $18(3)$ & $0.6(1)$ & 301 & 15.77 \\
\hline $67.95(3)$ & $31(7)$ & $0.3(1)$ & 311 & 31.82 \\
\hline
\end{tabular}

Table 5 Specific capacitance of the composites sample

\begin{tabular}{|ll|}
\hline Sample & Specific Capacitance $\left(\mathrm{Fg}^{-1}\right)$ \\
\hline PANI & 10.53 \\
\hline CUO & 10.11 \\
\hline PANI:CuO;APS & 24.37 \\
\hline
\end{tabular}



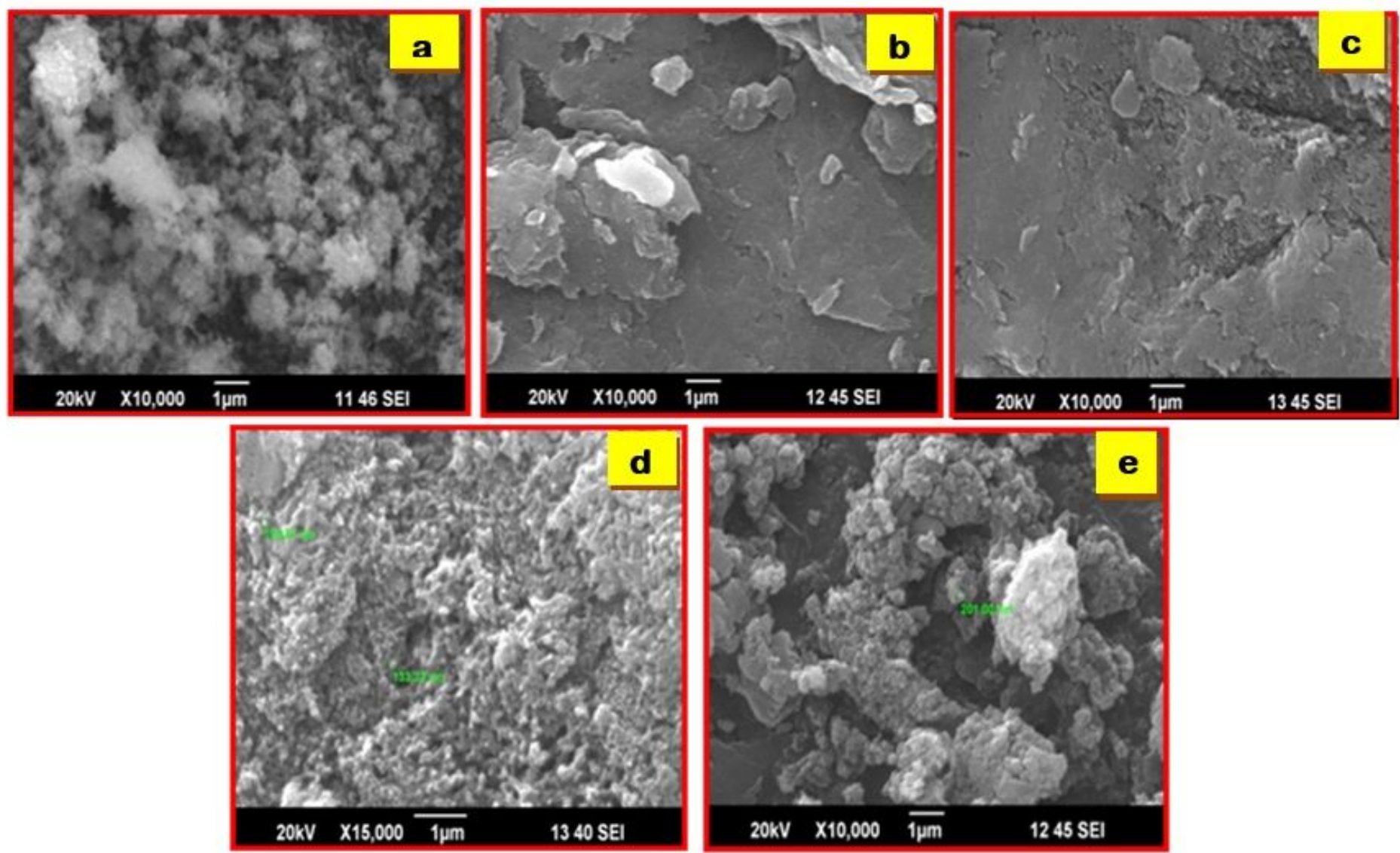

Figure 1

SEM images of (a) CuO and PANI:CuO:APSx hybrid nanocomposite Effects of APS (b) $0.1 \mathrm{M}$, (c) $0.15 \mathrm{M}$, (d) $0.3 \mathrm{M}$ and (e) $0.5 \mathrm{M}$
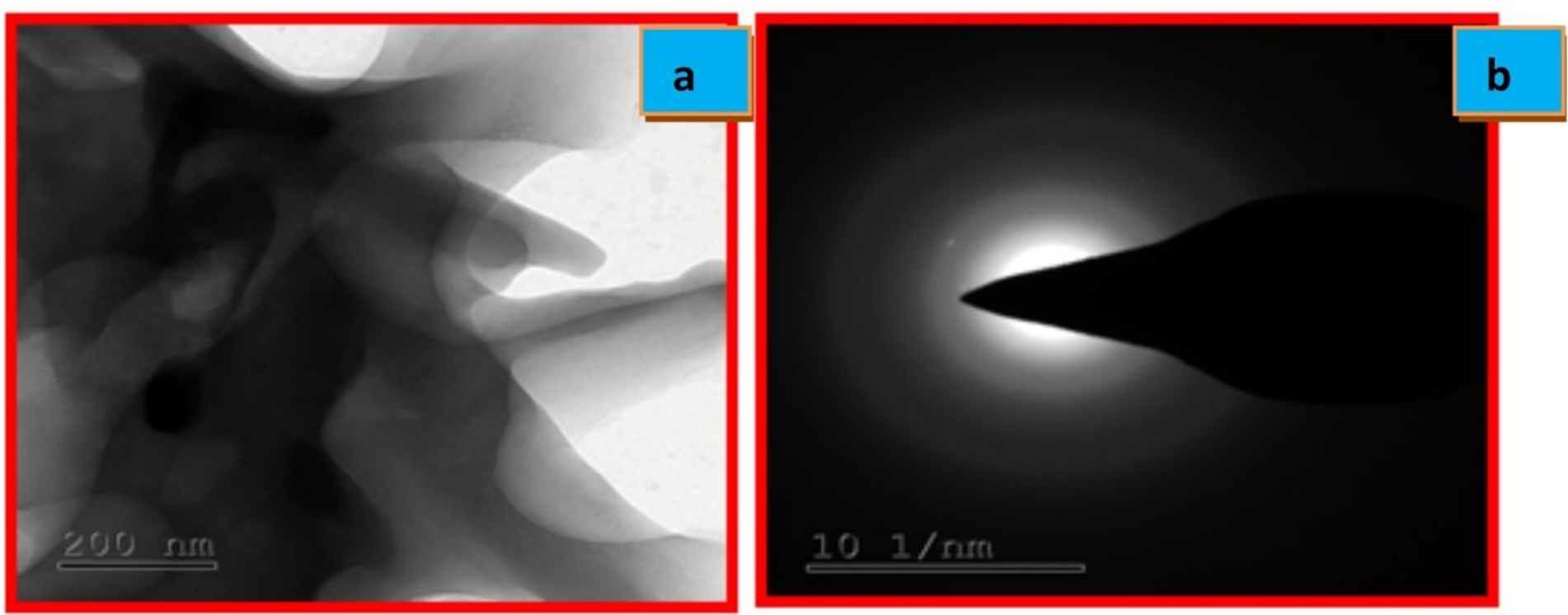

Figure 2

TEM images of (a) PANI:CuO hybrid nanocomposite and (b) SAED pattern 

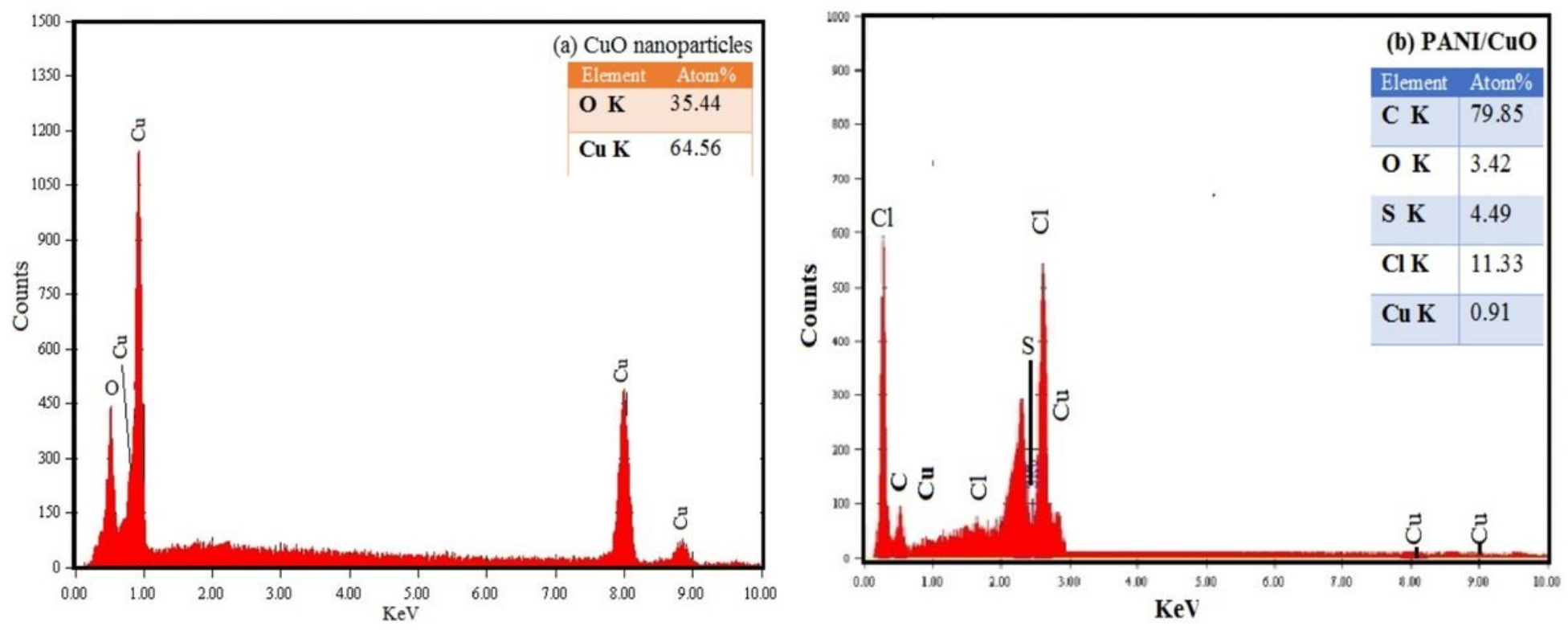

Figure 3

EDAX analysis of (a) CuO and (b) PANI:CuO hybrid nanocomposite 


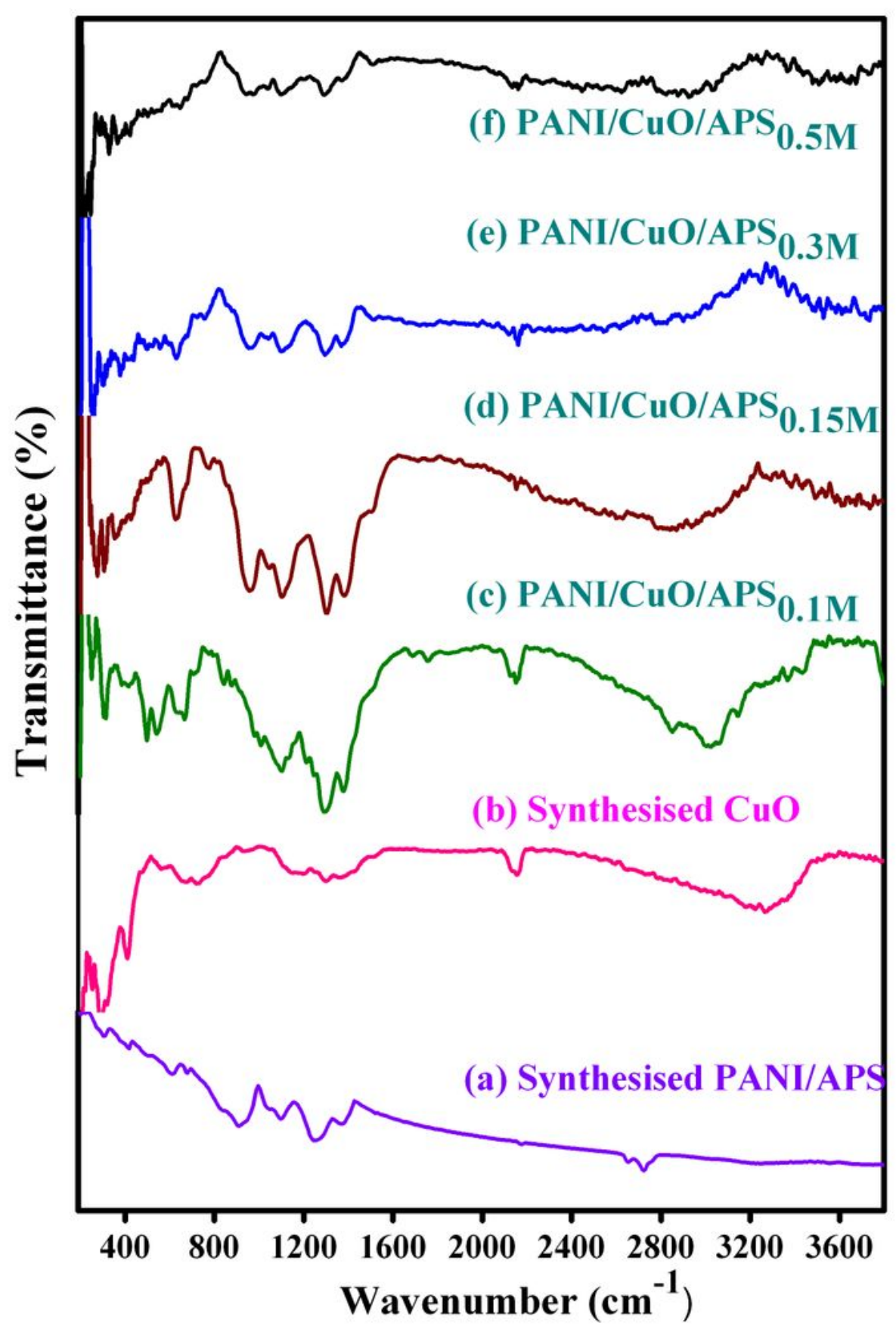

Figure 4

FT-IR spectra of (a) PANI, (b) CuO and (c-f) PANI:CuO:APSx hybrids 


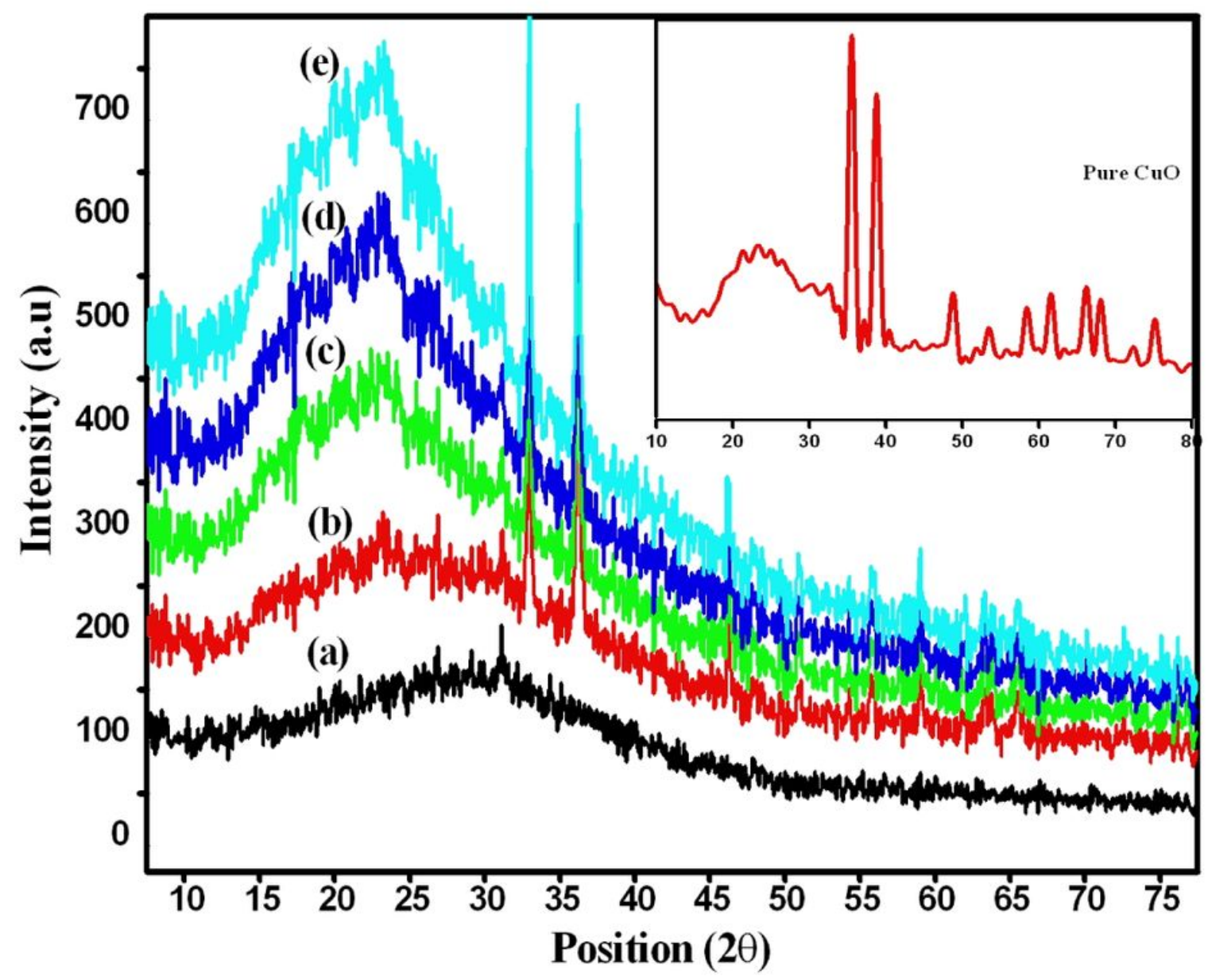

Figure 5

XRD pattern of (a) PANI and PANI:CuO:APSx hybrid nanocomposite: Effects of APS (b) $0.1 \mathrm{M}$, (c) $0.15 \mathrm{M}$, (d) $0.3 \mathrm{M},(\mathrm{e}) 0.5 \mathrm{M}$ (inset CuO) 

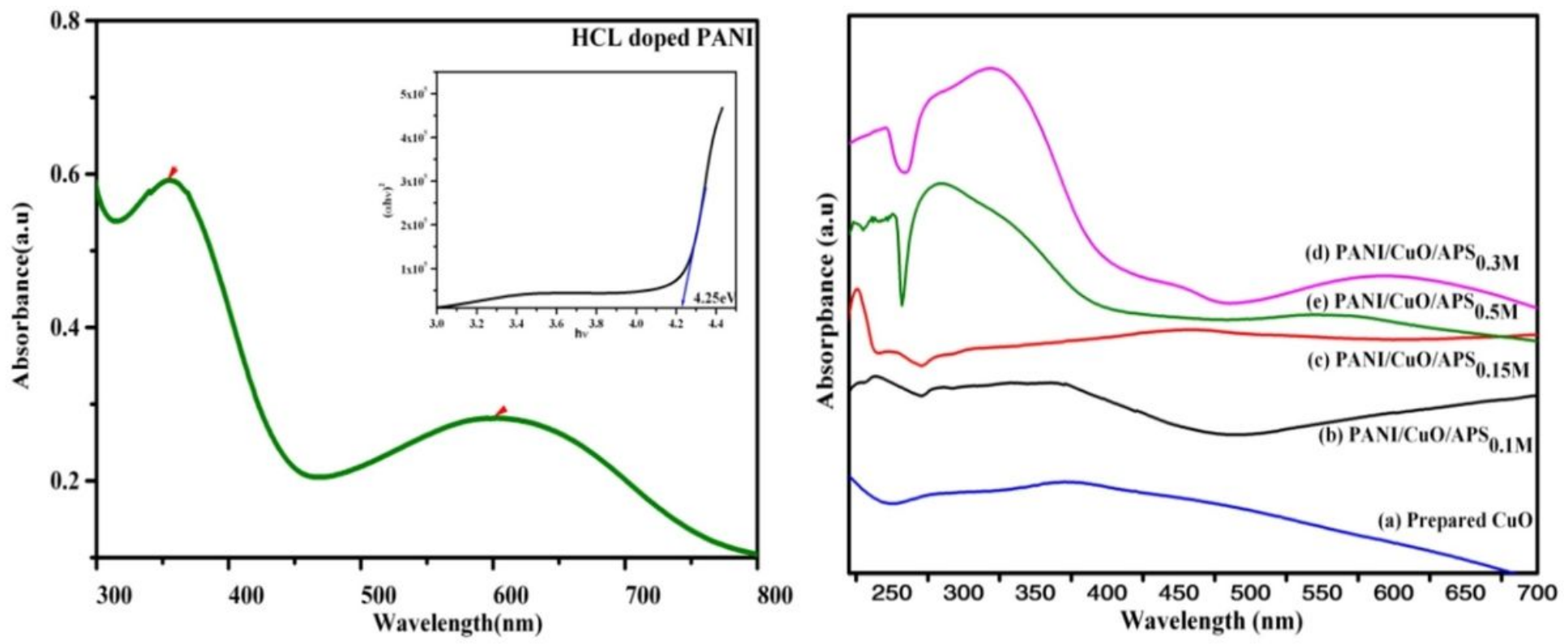

Figure 6

UV-Vis spectra of (a) PANI (b) PANI:CuO:APS $x$ hybrid nanocomposites: Effects of APS ( $x=0.1,0.15,0.3$ and $0.5 \mathrm{M}$ ) 


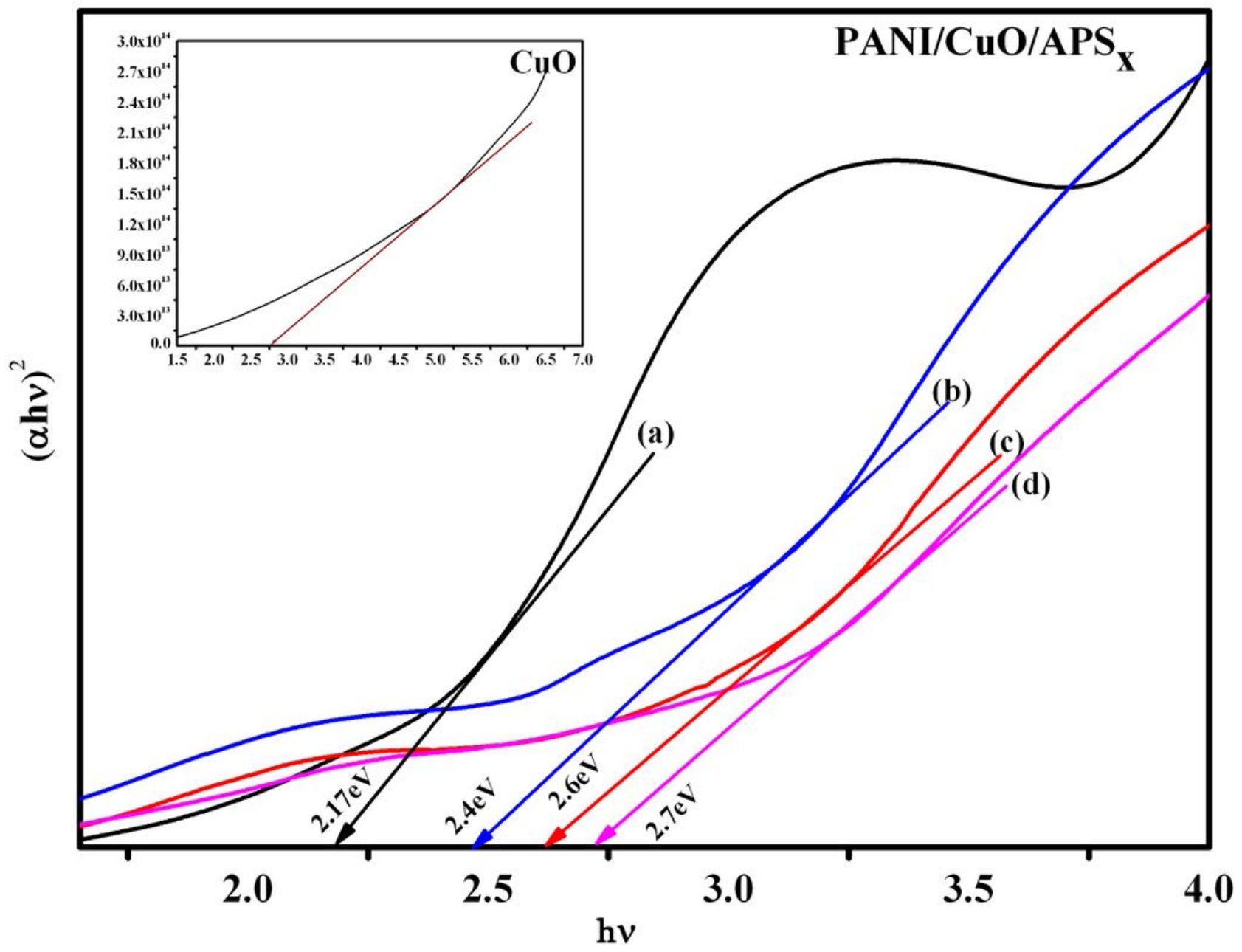

Figure 7

Relation between $(\alpha \mathrm{h} v) 2$ and hv for PANI:CuO:APS $x$ hybrid nanocomposites: Effects of oxidants $(\mathrm{x}=0.1$, $0.15,0.3$ and $0.5 \mathrm{M})$ 


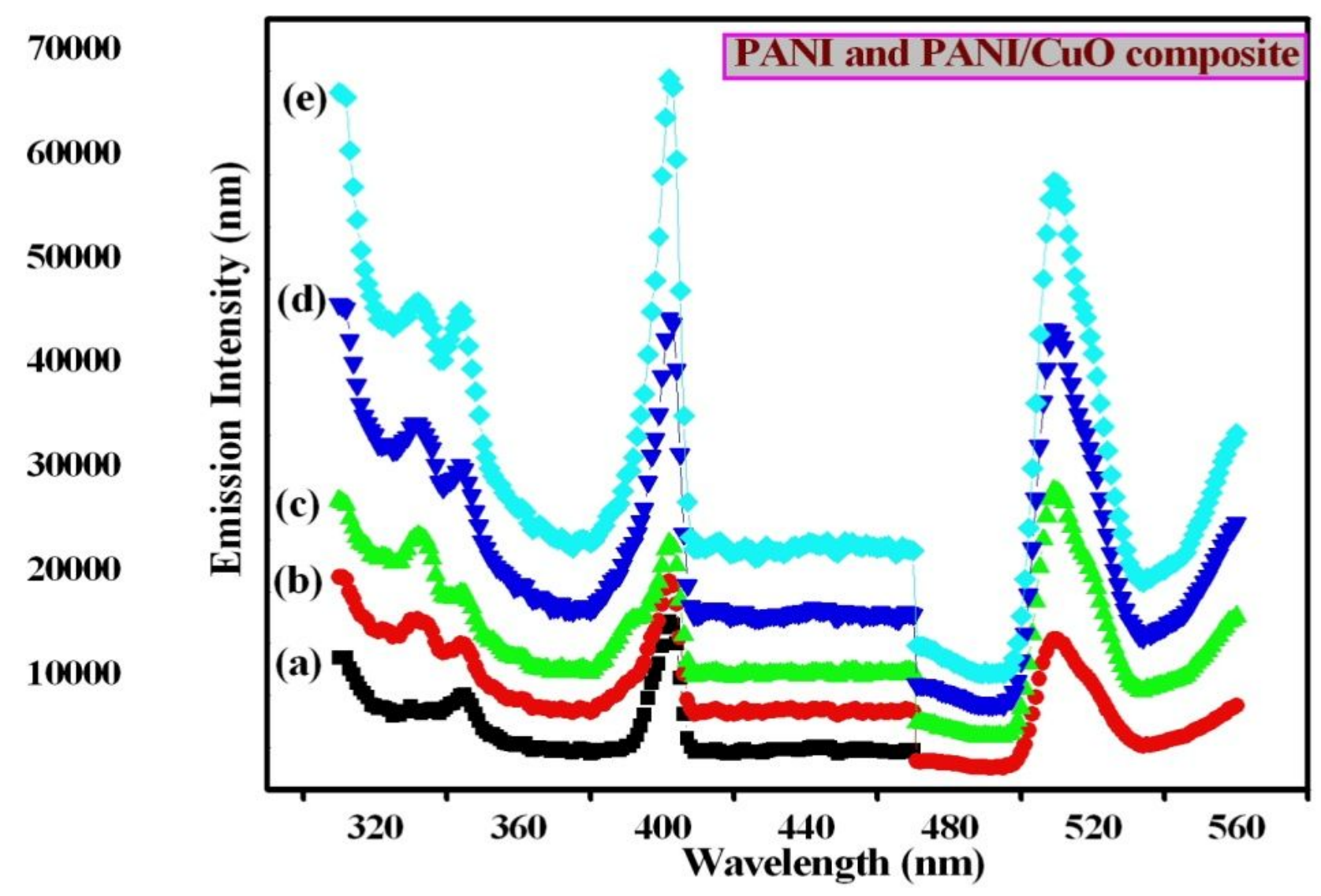

Figure 8

PL spectra of (a) $\mathrm{HCl}$ doped polyaniline and PANI:CuO:APSx hybrid nanocomposites: Effects of APS (b) $0.1 \mathrm{M},(\mathrm{c}) 0.15 \mathrm{M},(\mathrm{d}) 0.3 \mathrm{M}$ and (e) $0.5 \mathrm{M}$ 

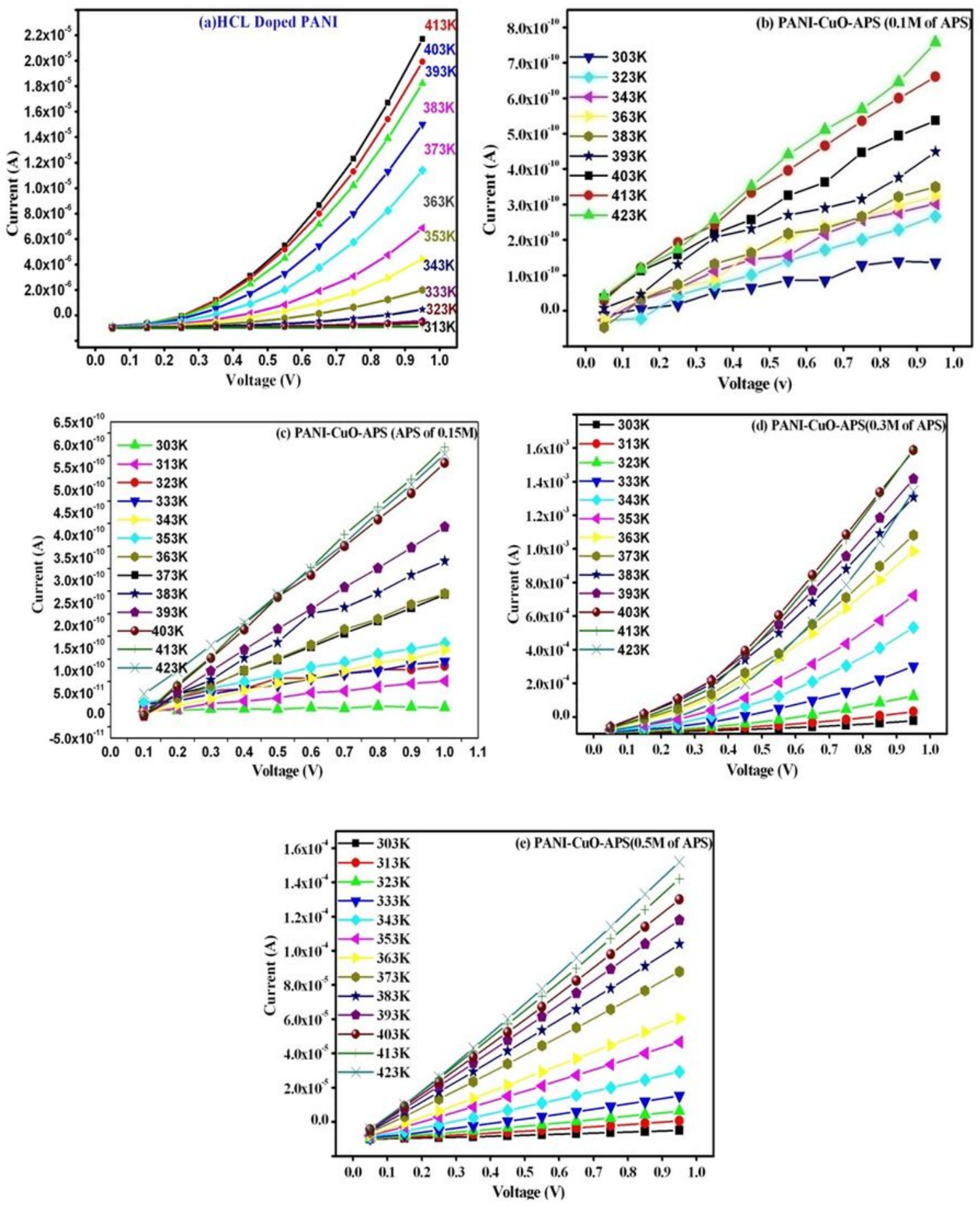

\section{Figure 9}

I-V characteristics of (a) PANI, (b-e) PANI:CuO:APSx hybrid nanocomposite: Effects of APS (0.1-0.5 M) 


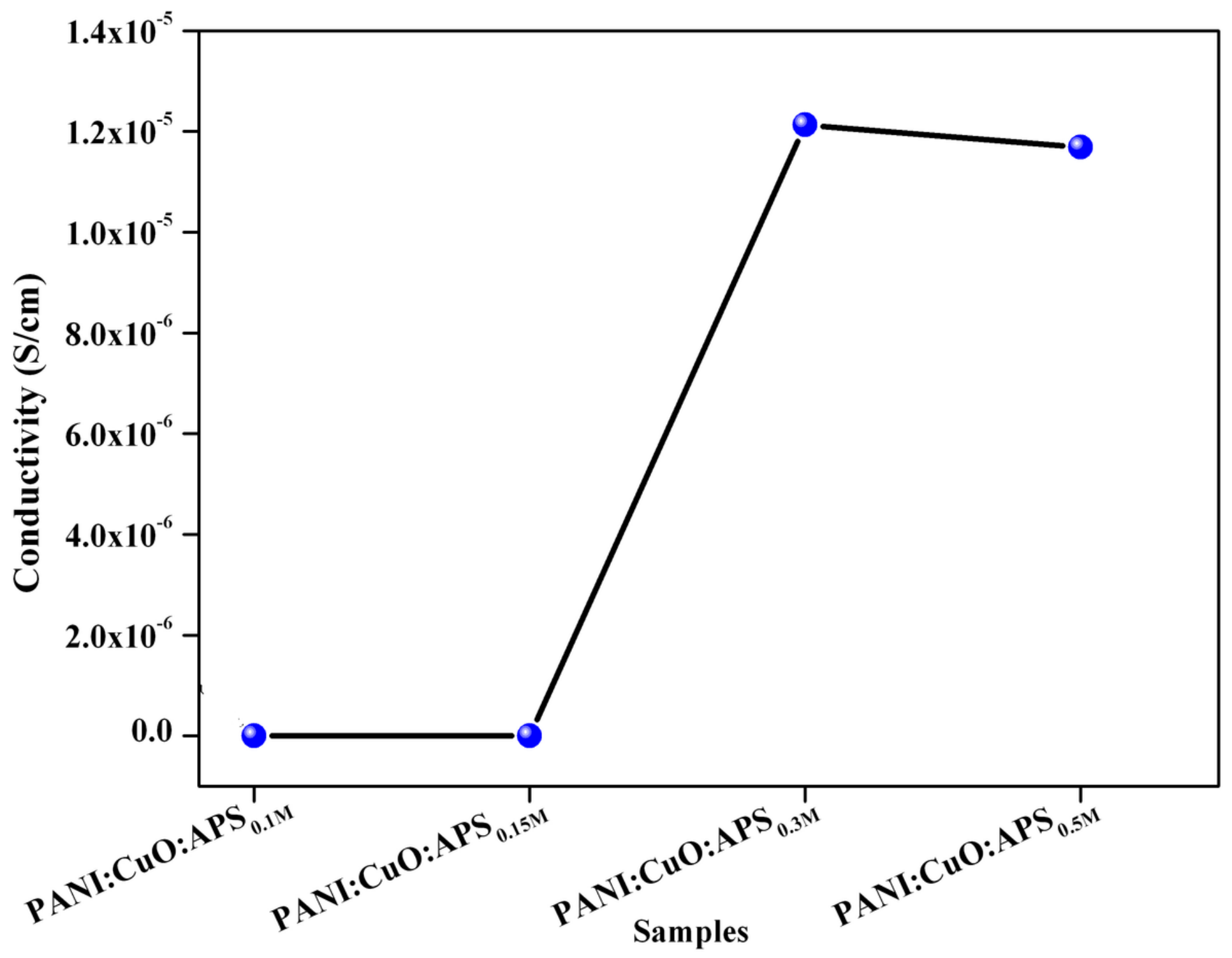

Figure 10

DC conductivity of PANI:CuO:APSx hybrid nanocomposites: Effects of APS 

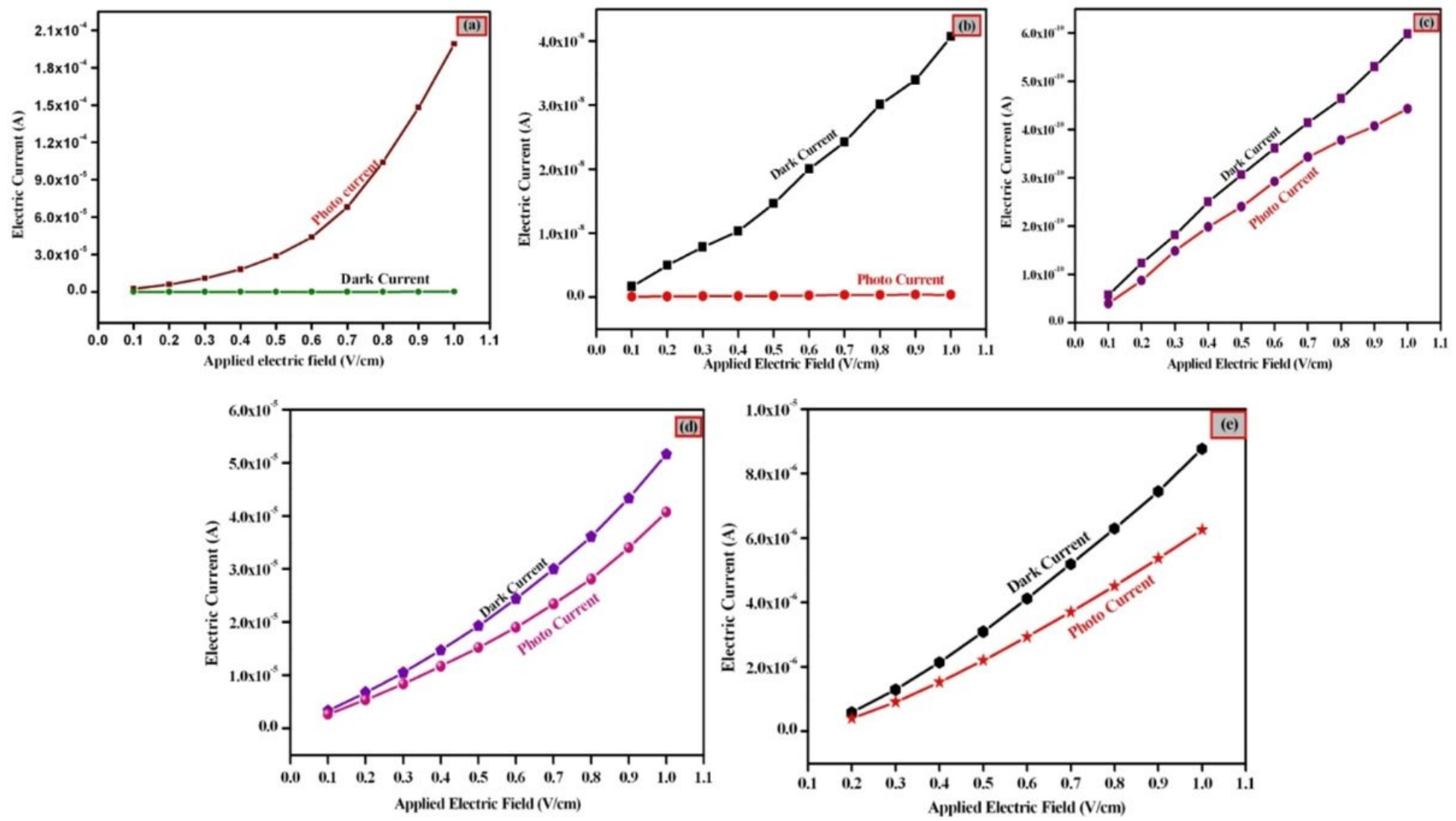

Figure 11

Photoconductivity study of (a) PANI and (b-e) PANI:CuO:APSx hybrid nanocomposites: Effects of APS $(x=0.1,0.15,0.3$ and $0.5 \mathrm{M})$ 

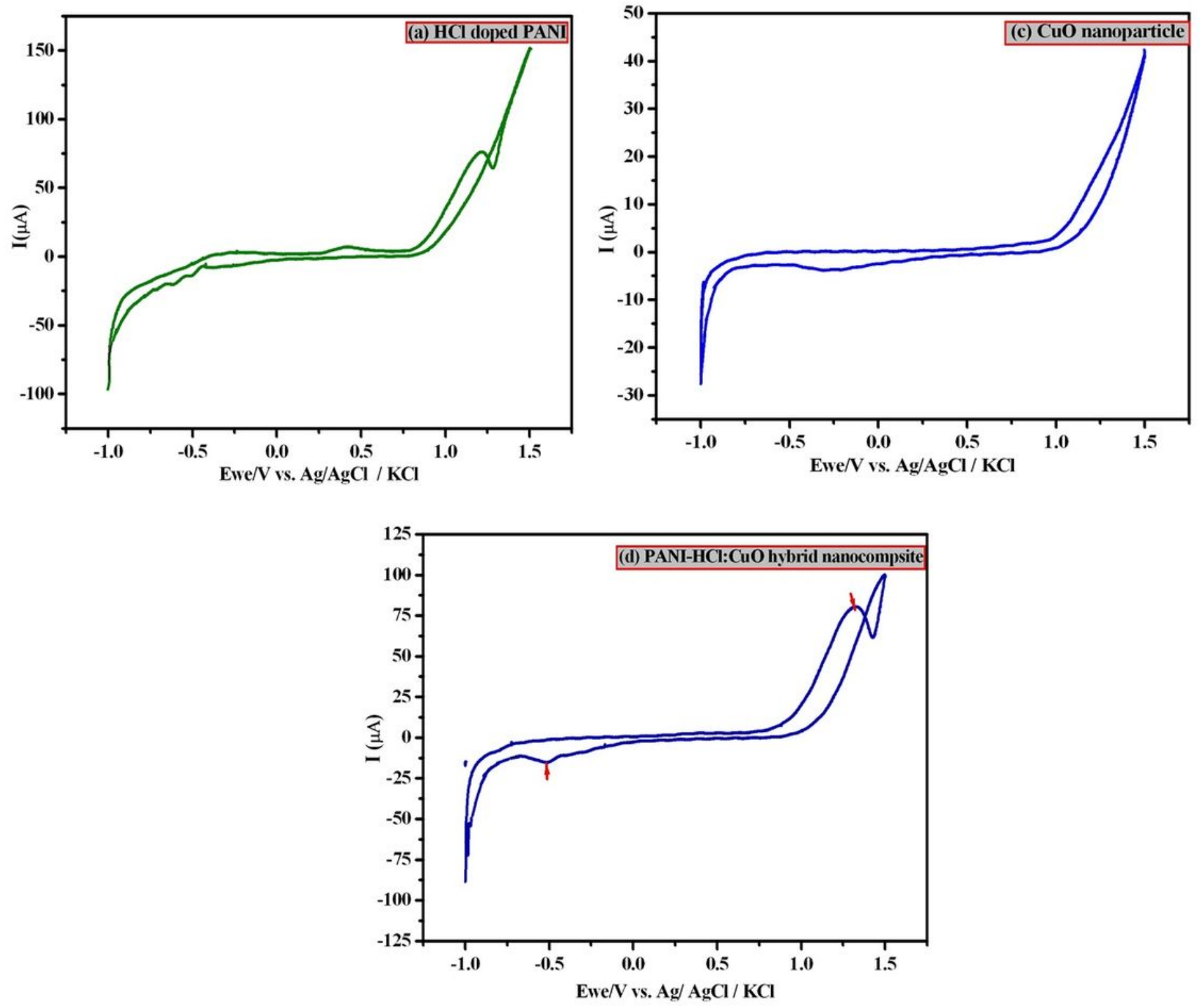

Figure 12

Cycle Voltammetry curves of (a) PANI, (b) CuO and (c) PANl:CuO hybrid nanocomposites 